\title{
Screening and managing depression in adolescents
}

This article was published in the following Dove Press journal:

Adolescent Health, Medicine and Therapeutics

10 August 2010

Number of times this article has been viewed

\author{
Jami F Young \\ Michelle R Miller \\ Nida Khan \\ Department of Clinical \\ Psychology, Graduate School \\ of Applied and Professional \\ Psychology, Rutgers University, \\ Piscataway, NJ, USA
}

Correspondence: Jami FYoung Applied and Professional Psychology, Graduate School of Applied and Professional Psychology, Rutgers University, 152 Frelinghuysen Road, Piscataway, NJ 08854, USA

Email jfyoung@rci.rutgers.edu
Abstract: Approximately $10 \%-15 \%$ of adolescents will experience a major depressive episode. The risk factors associated with depression in adolescence include a family history of depression, being female, subthreshold depression, having a nonaffective disorder, negative cognitions, interpersonal conflict, low social support, and stressful life events. Despite the availability of measures to identify depressed adolescents and efficacious interventions to treat these adolescents, a large number of depressed adolescents go undetected and untreated. This review describes several screening measures that can be used to identify adolescents with elevated depression symptoms who would benefit from a comprehensive diagnostic evaluation. If an adolescent is diagnosed with a depressive disorder, there are several efficacious treatment options, including pharmacotherapy, cognitive behavior therapy, and interpersonal psychotherapy. The research supporting each of these approaches is outlined, and recommendations are made to help health professionals determine the appropriate course of treatment. Although existing treatments are effective for many depressed adolescents, approximately one-third of adolescents remain depressed following treatment. Continuing research is needed to enhance the efficacy of existing treatments for adolescent depression and to develop and study novel treatment approaches.

Keywords: treatment, medication, psychotherapy

\section{Prevalence of depression in adolescents}

Adolescent depression is a serious mental health problem. Approximately $15 \%$ of adolescents will experience a major depressive episode. ${ }^{1}$ At any given point in time, $5 \%$ of adolescents will meet criteria for a depression diagnosis. ${ }^{2}$ The risk factors associated with depression in adolescence include a family history of depression, being female, subthreshold depression, having a nonaffective disorder, negative cognitions, interpersonal conflict, low social support, and stressful life events..$^{3-10}$ Depression in adolescence is associated with significant impairment in functioning and an increased risk for developing a future major depressive episode and other psychiatric disorders. ${ }^{11-13}$ Despite the availability of measures to identify depressed adolescents and efficacious interventions to treat these adolescents, a large number of depressed adolescents go undetected and untreated. Furthermore, when treatment is sought in the community, the services provided are often quite brief and do not involve evidencebased approaches. ${ }^{14,15}$

The goal of this review is to provide health professionals with adequate knowledge to identify adolescents who are experiencing depression and to determine the most appropriate treatment option. To meet this goal, the review will summarize and 
critique existing screening and diagnostic tools for adolescent depression, will describe the current evidence base for treating adolescent depression, and will provide recommendations that will help health professionals choose the most appropriate course of treatment for a given adolescent. Information for this review was obtained through computer searches on PsycINFO and MEDLINE and examination of relevant review articles, meta-analyses, and practice parameters. Keywords used in the searches were depression, antidepressant, psychotherapy, and rating scales, combined with the term adolescent.

\section{Screening and diagnosing depression in adolescents}

Recognition of the considerable risk and impairment associated with depression symptoms and diagnoses in adolescence led the US Preventive Services Task Force to recommend that adolescents be screened for major depressive disorder (MDD) when systems are in place to ensure accurate diagnosis, treatment, and follow-up. ${ }^{16}$ Screening identifies those individuals who are at risk for meeting clinical criteria for a depressive episode, and hence, is the first of two steps for arriving at a diagnosis. Following screening, clinician-administered measures of depression or a semistructured diagnostic interview may be helpful in distinguishing between subthreshold and clinical depressions. ${ }^{17}$ A multimethod assessment approach for evaluating depression in adolescents is recommended. ${ }^{18}$ In the following section, we review the most widely used and well-researched depression rating scales and diagnostic interviews.

Several self-report measures of depression have been used to screen adolescents for depressive symptoms. Given the poor construct validity of many of these measures and their low specificity, these measures are recommended as screening instruments and not to determine whether an adolescent meets criteria for a depressive diagnosis. ${ }^{18,19}$ One of the most commonly used measures is the Beck Depression Inventory (BDI). ${ }^{20,21}$ The BDI is a 21 -item self-report measure of depression that was developed for adults, but has been used extensively with adolescents. A BDI score of 16 has been recommended as a cutoff score to indicate a depressive disorder. Several studies have attested to the strong psychometric properties of the BDI in adolescents. ${ }^{22-26}$ However, the BDI does not assess severity of depression in adolescents as effectively as it does with adults, resulting in a high false-positive rate. ${ }^{22,27}$

Another commonly used screening instrument is the Center for Epidemiologic Studies-Depression Scale
(CES-D). ${ }^{28}$ The CES-D is a 20 -item self-report measure of depression that was developed for adults. It has been well researched and tested as a screening tool for adolescent depression..$^{27,29-31}$ The adult literature recommends using a CES-D score of 16 or higher as indicative of a depressive illness. Because a cutoff of 16 leads to false positives in adolescents, various cutoff scores ranging from 12 to 24 have been recommended. ${ }^{29,30}$ Even with these different cutoffs, the CES-D leads to a high rate of false positives. ${ }^{19,27}$

The Children's Depression Inventory (CDI), which is an extension of the BDI for children and adolescents, is a 27-item measure that is appropriate for children aged 7-18. ${ }^{32}$ There is also a parent-report version of the CDI. Although the CDI has good reliability data, there are concerns about its construct validity, with research suggesting that the CDI measures general distress rather than depression. ${ }^{33}$ Another well-known measure of adolescent depression is the Reynolds Adolescent Depression Scale (RADS), which was revised in 2002 (RADS-2). ${ }^{34,35}$ The RADS-2 is a 30 -item selfreport measure of depression, which has an accompanying parent-report form. Unlike many other self-report measures, the RADS scales are based on the diagnostic criteria for depression. A score of 76 or higher on the RADS- 2 indicates elevated depression symptoms requiring further diagnostic evaluation. ${ }^{35}$ The RADS-2 is a promising screening tool, but additional research is needed to clarify issues of sensitivity and specificity. ${ }^{19}$

Recognizing the need for a multimethod assessment of depression in adolescence, treatment studies typically include one of the self-report measures discussed above, a clinician-administered measure of depression, and a semistructured diagnostic interview. Although clinician-administered measures and semistructured interviews are not typically used in clinical settings, they may be helpful in assessing depression in these settings. ${ }^{18}$ The 2 most commonly used clinician-administered measures are the Hamilton Rating Scale for Depression and the Children's Depression Rating Scale-Revised..$^{36-38}$ The most commonly used diagnostic interview for depression is the Schedule for Affective Disorders and Schizophrenia for School-Age Children - Present and Lifetime (K-SADS-PL) version. ${ }^{39}$ The K-SADS-PL is a semistructured diagnostic interview that assesses current and past episodes of psychopathology in children and adolescents according to Diagnostic and Statistical Manual of Mental Disorders (fourth edition) (DSM-IV) criteria. Additional semistructured and structured diagnostic evaluations are available, such as the Diagnostic Interview for Children and Adolescents, the Child and Adolescent Psychiatric 
Assessment, and the Diagnostic Interview Schedule for Children. ${ }^{40-42}$ For more information on these interviews, the readers are referred to two comprehensive reviews of these measures. ${ }^{43,44}$ The advantage of diagnostic interviews is that they help clinicians make a depression diagnosis and evaluate other comorbid conditions that may impact treatment planning. Although there is limited data on the use of these diagnostic tools in clinical practice, the evidence suggests that semistructured and structured diagnostic interviews may lead to more reliable diagnoses than unstructured clinical assessments. $^{45,46}$

\section{Treatment of adolescent depression}

The 2 primary approaches for treating adolescent depression are pharmacotherapy and psychotherapy. ${ }^{18}$ With regard to medications, tricyclic antidepressant medications have shown limited efficacy in treating youth depression and are associated with negative side effects. ${ }^{47}$ For these reasons, research has focused more on the use of selective serotonin reuptake inhibitors (SSRIs). Although there is evidence from several randomized clinical trials to support the use of certain SSRIs with depressed adolescents, there are also several negative trials of SSRIs with this population. ${ }^{48}$ Fluoxetine has shown more consistent efficacy in the treatment of youth depression than the other SSRIs. ${ }^{4-51}$ Until recently, fluoxetine was the only medication approved by the US Food and Drug Administration (FDA) for the treatment of adolescent depression. In March 2009, escitalopram was also approved by the FDA for the acute and maintenance treatment of depression in adolescents based on the positive findings of a recently completed trial of escitalopram and an earlier study of citalopram..$^{52,53}$

A particular concern in regard to the use of SSRIs in adolescents has been the risk of adverse events, particularly increased suicidal ideation and behavior. ${ }^{54}$ Whittington et al analyzed both published and unpublished randomized controlled trials on the use of different SSRIs for depression in children and adolescents to assess the benefits and risks of these medications. Although research on paroxetine and fluoxetine was comparable, paroxetine showed limited efficacy and a greater chance of adverse events. The limited number of studies on sertraline, venlafaxine, and at the time, citalopram also demonstrated weak evidence of efficacy and a stronger likelihood for adverse events in comparison with fluoxetine..$^{55}$ In 2004, the FDA examined the data on suicidality in children and adolescents taking antidepressant medication and concluded that a warning, indicating a small chance of suicidality, needed to be included on all antidepressant medication boxes. ${ }^{56}$ More recent analyses of the data on the use of SSRIs in pediatric populations suggest that the benefits of SSRIs in treating adolescent depression likely outweigh the risks. ${ }^{57}$ Furthermore, Gibbons et al found an association between higher SSRI prescription rates and lower suicide rates among children and adolescents. ${ }^{58}$ Additional analyses of the risk/benefit ratio of SSRIs are needed to clarify this issue.

Given the concerns about antidepressant medications for youth and many families' preference for psychosocial treatments, several psychotherapeutic interventions have been developed for adolescent depression. Cognitive behavior therapy (CBT) is the most studied psychosocial intervention for youth depression and is considered a well-established model of treatment for this population. ${ }^{59,60} \mathrm{CBT}$ is based on the theory that depression stems from maladaptive thoughts and behaviors. Although there are many different CBT treatments that have been developed to target adolescent depression, three treatment manuals have the most empirical support: Coping with Depression for Adolescents (CWD-A), the Cognitive Therapy Manual for Depressed and Suicidal Youth, and a brief CBT intervention developed and tested in the United Kingdom. ${ }^{61-63}$ Other CBT interventions have been designed for depressed children and early adolescents, but a discussion of these programs is beyond the scope of this article. ${ }^{64,65}$

CWD-A is a group intervention that focuses on psychoeducation, increasing pleasant activities, cognitive restructuring, social skills training, and problem solving. ${ }^{61}$ CWD-A has been used with and without parent sessions. Lewinsohn et al randomly assigned a sample of depressed adolescents to CWD-A with or without a parent group or a wait-list control for 14 sessions. Both CWD-A groups did better than wait-list control, with no significant differences between the two CWD-A interventions. ${ }^{66}$ In a later study that included a larger number of participants and booster sessions over a 24-month posttreatment period, the CWD-A groups performed better in treating depression than the control group, and no difference was found with the addition of the parent component. Although the booster sessions did not reduce recurrence of depression, participants who were still depressed after the treatment and received booster sessions continued to experience reductions in depression symptoms. ${ }^{67}$

In the past decade, CWD-A's effectiveness has been further demonstrated in research with a variety of adolescent populations, including depressed adolescents with comorbid conduct disorder and depressed adolescents in Puerto Rico. ${ }^{68,69}$ A modification of CWD-A, the Coping with Stress 
Program, has been studied as an indicated and selective preventive intervention for adolescent depression. ${ }^{70-73}$ In a recent review, Cuijpers et al summarized the studies that have used this intervention approach with adolescents, both as a treatment and preventive model. ${ }^{74}$ The American Psychological Association's (APA) Task Force has classified group CBT as a well-established treatment approach for adolescent depression. The CWD-A manual is considered probably efficacious, given the limited number of replication studies by independent investigators. ${ }^{60}$

The Cognitive Therapy Manual for Depressed and Suicidal Youth is an individual treatment, lasting 12-16 sessions. ${ }^{62}$ It primarily emphasizes cognitive restructuring and psychoeducation, but also incorporates behavioral activation and problem-solving training, depending on the individual case. In contrast to CWD-A, there are no specific exercises or homework in the manual, and there is more flexibility to adapt the manual to individual cases. ${ }^{75}$ Brent et al examined the impact of their CBT approach on adolescent depression in comparison with family systems therapy and supportive therapy. Adolescents who received the CBT intervention were less likely to meet criteria for MDD following treatment than those in supportive therapy and had a significantly higher rate of remission than adolescents in either family therapy or supportive therapy. ${ }^{76}$ There were no significant differences in long-term outcomes among the three treatment conditions at 2-year follow-up. ${ }^{77}$ The Cognitive Therapy Manual for Depressed and Suicidal Youth is considered a probably efficacious treatment for adolescent depression. ${ }^{60}$

Vostanis et al created a brief CBT program for adolescent depression that involves 5-8 sessions beginning with goal setting, emotional recognition, and self-monitoring, and then, depending on the client's needs, problem solving, activity scheduling, and/or challenging negative thoughts. ${ }^{63}$ Although this manual was more effective in reducing depression symptoms compared with relaxation training in a clinical setting, there was no difference found between the approach and routine care when it was delivered in a community setting by social workers trained in the approach. ${ }^{78,79}$ Due to the limited number of studies, this brief CBT approach has been classified as experimental by the APA Task Force. ${ }^{60}$

Another well-researched psychological intervention for depressed adolescents is Interpersonal Psychotherapy for Depressed Adolescents (IPT-A). ${ }^{80}$ IPT-A, a 12- to 16-week individual treatment, is based on the concept that depression occurs in an interpersonal context. IPT-A conceptualizes depression as a medical illness that interferes with the daily life of the adolescent. The intervention emphasizes psychoeducation about depression, creating a detailed assessment of adolescents' relationships with others, modification of communication patterns, teaching interpersonal problem solving, and involvement of the parent in therapy. In an initial efficacy study of IPT-A, depressed adolescents were randomized to receive either IPT-A or clinical monitoring. At the end of treatment, significantly more adolescents in IPT-A met recovery criteria for major depression than adolescents in clinical monitoring. ${ }^{81}$ An effectiveness study was conducted that compared IPT-A as delivered by school counselors with treatment as usual in school-based health clinics with depressed adolescents. ${ }^{82}$ Adolescents who received IPT-A demonstrated a significantly greater decrease in depression symptoms and depression severity and a greater improvement in overall functioning compared with adolescents who received treatment as usual.

Rosselló and Bernal created an adaptation of IPT that was designed specifically for depressed adolescents in Puerto Rico. ${ }^{83}$ They compared this version of IPT with CBT and a wait-list condition. Depressed adolescents receiving IPT or CBT experienced a greater reduction in symptoms and more improvement in social functioning than adolescents in the wait-list condition. The APA Task Force has classified the IPT model of treatment as well established, while the specific manuals are considered probably efficacious due to the lack of replication by an independent research group..$^{60}$

Although CBT and IPT are the most studied therapeutic models for adolescent depression, other interventions have also been developed. Diamond et al developed AttachmentBased Family Therapy (ABFT) for depressed adolescents based on structural and multidimensional family therapy. ${ }^{84}$ ABFT posits that resolving family attachment problems and improving adolescents' sense of competency are critical to treating adolescent depression. This is accomplished by reframing the problem from the adolescent to impaired family relationships, building alliance with the adolescent and with parents, working with the parents and adolescent to rebuild attachment, and promoting the adolescent's sense of competency. ${ }^{85}$ In a pilot study, Diamond et al compared 12 weeks of ABFT with 6 weeks of a wait-list control. Following the intervention, $80 \%$ of adolescents receiving ABFT compared with $47 \%$ of adolescents in the wait-list control condition were no longer experiencing MDD. ${ }^{84}$ Based on this preliminary study, the APA Task Force classified ABFT as an experimental treatment in need of further study. ${ }^{60}$ Since that review, an additional study of ABFT for adolescents with suicidal ideation found that adolescents in ABFT had significantly greater reductions in suicidal ideation 
than adolescents in usual care. Adolescents in ABFT also showed reductions in depressive symptoms, although the rates of change in the two conditions were not significantly different. ${ }^{86}$

Weisz et al conducted a meta-analysis of psychological interventions for depressed children and adolescents involving 35 studies. ${ }^{87}$ Current psychotherapies for depression in adolescents and children demonstrated a mean effect size of 0.34 , which is between Cohen's benchmarks for a small to medium effect. ${ }^{87}$ An effect size is a standardized mean difference between treatment and control groups that is expressed in standard deviation units. An effect size of 0.34 indicates that the average adolescent who received treatment for depression was at the 63rd percentile of the control group following treatment. ${ }^{88}$ These effects indicate that some adolescents who receive psychological treatments for depression do not improve. There were no effect size differences between cognitive and noncognitive interventions or group and individual modalities. Given that the effects of existing psychosocial interventions for depression are modest, additional research is needed to enhance these interventions and/or develop novel treatments. In addition, more information is needed on the long-term effects of these interventions. ${ }^{14}$

Research has also compared psychotherapy and medication for adolescent depression and examined the benefits of a combined treatment approach. Clarke et al compared adolescents receiving SSRIs through $\mathrm{HMO}$ pediatric primary care (usual care) with adolescents receiving usual care plus a brief version of CBT. ${ }^{89}$ The CBT program, based on the CWD-A manual, was designed for 5-9 sessions and entailed the use of modules for cognitive restructuring and/ or behavioral activation. Although the combination of SSRIs and CBT had an advantage on a few measures, adolescents in combined treatment did not show significantly greater reductions in depression symptoms or rates of recovery than adolescents in the usual-care-only condition. Given that $75 \%$ of adolescents in usual care reported depression recovery by the 12-week follow-up, the study was likely underpowered to detect any additive effects of the CBT intervention. In addition, the CBT program may have been too brief to yield additional effects beyond the medication. ${ }^{89}$

In the multisite Treatment of Adolescents with Depression Study (TADS), adolescents with MDD were randomized to receive $\mathrm{CBT}$ alone, fluoxetine alone, $\mathrm{CBT}$ plus fluoxetine, or a placebo pill to compare short-term efficacy and longterm effects. ${ }^{51}$ Adolescents who received a combination of CBT and medication had the greatest decrease in depression symptoms and a higher rate of remission at the end of treatment than adolescents in the other conditions. ${ }^{51,90}$ Posttreatment, fluoxetine alone was superior to placebo, whereas CBT alone did not differ significantly from the placebo condition. ${ }^{51}$ The effect size for CBT in TADS was smaller than the psychotherapy effect sizes found in previous research with depressed youth. The adolescents in TADS were more severely ill and had more comorbid conditions than the adolescents in prior studies of CBT. CBT may not be effective as a stand-alone treatment for more severely depressed adolescents. ${ }^{91}$ The CBT manual used in TADS was based on CWD-A and the Cognitive Therapy Manual for Depressed and Suicidal Youth and included multiple CBT modules that the therapist could choose to implement. ${ }^{61,62,92}$ It is possible that any one module may have been delivered at a lower dose than necessary for CBT to demonstrate efficacy. ${ }^{59,91}$ Further research is needed to better understand how antidepressant medication compares to psychotherapy and to examine the benefits of combined treatment.

The combination of antidepressant medication and an evidence-based psychotherapy may be beneficial for adolescents who do not respond to a course of monotherapy. The multisite Treatment of SSRI-Resistant Depression in Adolescents (TORDIA) study was conducted to determine the best treatment approach for these adolescents. Depressed adolescents who had been treated with an SSRI but continued to meet criteria for MDD were randomly assigned to one of the following conditions: a different SSRI, a different SSRI plus CBT, venlafaxine, or venlafaxine with $\mathrm{CBT} .{ }^{93}$ The CBT intervention was based on the CWD-A manual, the Cognitive Therapy Manual for Depressed and Suicidal Youth, and the TADS manual. ${ }^{61,62,92}$ The 12-session treatment consisted of cognitive restructuring, behavioral activation, emotional regulation, social skills, and problem solving, as well as the option of 3-6 family sessions. The highest response rate was found in adolescents who received a combination of CBT with either medication, but there was no difference between the medications. ${ }^{93}$ Thus, depressed adolescents who do not respond to their first trial with an SSRI may be best helped by switching to a new medication and undergoing CBT.

Based on the previously described literature, specific treatment guidelines for youth depression have been outlined by the American Academy of Child and Adolescent Psychiatry (AACAP). ${ }^{94}$ These guidelines recommend that following an initial diagnosis of mild depression, adolescents should be provided with support and monitoring for 6-8 weeks. Adolescents who do not respond to nondirective support and monitoring or have more moderate depression should 
be referred for CBT, IPT, or antidepressant medication. For adolescents with more severe depression, antidepressant medication is recommended. Based on the TADS and TORDIA findings, combination treatment consisting of an antidepressant and CBT or IPT should be considered for adolescents with severe or treatment-resistant depression. ${ }^{51,93}$ After a depressed adolescent has shown improvement for 6-8 weeks, the AACAP guidelines recommend that treatment continue, at a decreased frequency, for 6-12 months to prevent relapse. ${ }^{94}$

\section{Applicability of research findings to clinical practice}

Although research supports the use of SSRIs, CBT, and IPT for the treatment of adolescent depression, critics argue that the samples used in these studies are not representative of the more complex cases seen in clinical practice. ${ }^{15}$ The majority of adolescents in randomized controlled trials are recruited to participate through advertisements; they are not actively seeking treatment for their depression. ${ }^{95}$ In addition, both medication and psychotherapy trials tend to exclude adolescents with certain comorbidities, and so it is unclear whether these treatments are effective for adolescents with comorbid conditions. ${ }^{15}$ Finally, most of the studies, with the exclusion of those on IPT-A, have had predominately white, middle-class samples. As such, it is not clear how effective the psychosocial treatments are for ethnic minority groups. ${ }^{96,97}$ Despite these concerns, meta-analyses suggest that evidence-based therapies are superior to usual clinical care for youth mental health problems. ${ }^{15}$ As such, health professionals are encouraged to use research evidence to guide treatment decisions with depressed adolescents in clinical practice.

\section{Long-term outcomes of depression in adolescents}

Adolescent depression is a recurrent illness, with a third to half of individuals experiencing an additional episode within 3 years of recovery. ${ }^{98-100}$ Recurrence, in particular, is likely for adolescents who have a more severe depressive episode, have multiple depressive episodes during adolescence, or have family members with recurrent major depression. ${ }^{12}$ Given the high likelihood of recurrence, maintenance treatment is recommended..$^{94}$ Despite these recommendations, very little research has been conducted on maintenance psychotherapy or pharmacotherapy with depressed adolescents. The exceptions to this are the CWD-A study discussed earlier and the multisite TADS. ${ }^{67,51}$ In TADS, complete and partial responders went on to a 6-week continuation phase, when they were seen for psychotherapy or pharmacotherapy visits every 2 weeks, and then to an 18-week maintenance phase, when they were seen every 6 weeks. ${ }^{101}$ A larger percentage of adolescents met criteria for remission following continuation and maintenance treatment than did at the end of acute treatment. ${ }^{102}$ These findings highlight the importance of continuation and maintenance treatments, particularly for adolescents who show only a partial response at the end of treatment. Additional research is needed to determine the appropriate frequency and duration of these sessions.

\section{Conclusion}

Adolescent depression is widely prevalent and is associated with significant risk and impairment. Given the considerable risk and impairment associated with depression, it is important to identify, diagnose, and treat adolescents who are experiencing a major depressive episode. There are several well-studied measures that can act as a first-stage screen for depression in this age group. This screening should be followed by a comprehensive diagnostic evaluation to determine which adolescents meet criteria for depression, identify potential comorbidities, and better estimate the severity of the depressive episode. This diagnostic information will help determine the most appropriate treatment options. Research supports the use of pharmacotherapy, CBT, or IPT for the treatment of adolescent depression. Although these treatments are effective for many adolescents, approximately one-third of adolescents remain depressed following treatment, and a number of adolescents experience a relapse in later adolescence or adulthood. ${ }^{103}$ This suggests the need for further research to enhance existing treatment approaches, to develop and study novel treatments for adolescent depression, and to examine the appropriateness of depression interventions for various ethnic populations.

\section{Disclosure}

The authors report no conflicts of interest in this work.

\section{References}

1. Kessler RC, Walters MS. Epidemiology of DSM-III-R major depression and minor depression among adolescents and young adults in the national comorbidity survey. Depress Anxiety. 1998;7:3-14.

2. Lewinsohn PM, Hops H, Roberts RE, Seeley JR, Andrews AA. Adolescent psychopathology: I. Prevalence and incidence of depression and other DSM-III disorders in high school students. J Abnorm Psychol. 1993;102:133-144.

3. Lewinsohn PM, Rohde P, Seeley JR. Major depressive disorder in older adolescents: prevalence, risk factors, and clinical implications. Clin Psychol Rev. 1998;18:765-794.

4. Caspi A, Sugden K, Moffit TE, et al. Influence of life stress on depression: moderation in the 5-HTT gene. Science. 2003;301:386-389. 
5. Kendler KS, Kuhn JW, Vittum J, Prescott CA, Riley B. The interaction of stressful life events and a serotonin transporter polymorphism in the prediction of episodes of major depression: a replication. Arch Gen Psychiatry. 2005;62:529-535.

6. Weissman MM, Wickramaratne P, Nomura Y, et al. Families at high and low risk for depression: a 3-generation study. Arch Gen Psychiatry. 2005;62:29-36.

7. Rice F, Harold GT, Thapar A. Assessing the effects of age, sex and shared environment on the genetic etiology of depression in childhood and adolescence. J Child Psychol Psychiatry. 2002;43:1039-1051.

8. Goodman SH, Gotlib IH. Risk for psychopathology in the children of depressed parents: a developmental approach to the understanding of mechanisms. Psychol Rev. 1999;106:458-490.

9. Costello EJ, Pine DS, Hammen C, March JS, Plotsky PM, Weissman MM. Development and natural history of mood disorders. Biol Psychiatry. 2002;128:529-542.

10. Williamson DE, Birmaher B, Frank E, Anderson BP, Matty MK, Kupfer DJ. Nature of life events and difficulties in depressed adolescents. J Am Acad Child Adolesc Psychiatry. 1998;37:1049-1057.

11. Puig-Antich J, Kaufman J, Ryan ND, et al. The psychosocial functioning and family environment of depressed adolescents. $J \mathrm{Am}$ Acad Child Adolesc Psychiatry. 1993;32:244-253.

12. Lewinsohn PM, Rohde P, Klein DN, Seeley JR. Natural course of adolescent major depressive disorder: I. Continuity into young adulthood. J Am Acad Child Adolesc Psychiatry. 1999;38:56-63.

13. Fergusson DM, Woodward LJ. Mental health, educational, and social role outcomes of adolescents with depression. Arch Gen Psychiatry 2002;59:225-231.

14. Lewinsohn PM, Clarke GN. Psychosocial treatments for adolescent depression. Clin Psychol Rev. 1999;19:329-342.

15. Weisz JR, Jensen-Doss A, Hawley KM. Evidence-based psychotherapies versus usual clinical care: a meta-analysis of direct comparisons Am Psychol. 2006;61:671-689.

16. US Preventive Services Task Force. Screening for major depressive disorder in children and adolescents. Available from: http://www. ahrq.gov/clinic/uspstf/uspschdepr.htm Published 2009 Mar. Accessed Feb 27, 2010.

17. Horwitz AV, Wakefield JC. Should screening for depression among children and adolescents be demedicalized? J Am Acad Child Adolesc Psychiatry. 2009;48:683-687.

18. Birmaher B, Ryan ND, Williamson DE, Brent DA, Kaufman J. Childhood and adolescent depression: a review of the past 10 years. Part II. J Am Acad Child Adolesc Psychiatry. 1996;35:1575-1583.

19. Myers K, Winters NC. Ten-year review of rating scales. II: Scales for internalizing disorders. J Am Acad Child Adolesc Psychiatry. 2002; 41:634-659.

20. Beck AT, Steer RA. Beck Depression Inventory (BDI) Manual. 2nd ed. San Antonio, TX; Pearson Education; 1993.

21. Beck AT, Ward C, Mendelson M, Mock J, Erbaugh J. An inventory for measuring depression. Arch Gen Psychiatry.1961;4:53-63.

22. Ambrosini PJ, Metz C, Banc MD, Rabinovich H, Undie A. Concurrent validity and psychometric properties of the Beck Depression Inventory in outpatient adolescents. J Am Acad Child Adolesc Psychiatry. 1991; 30:51-57.

23. Teri L. The use of the Beck Depression Inventory with adolescents. J Abnorm Child Psychol. 1982;10:277-284.

24. Atlas JA, DiScipio WJ. Correlations of the Beck Depression Inventory and Reynolds Adolescent Depression Scale. Psychol Rep. 1992;73: 621-622.

25. Barrera M, Garrison-Jones CV. Properties of the Beck Depression Inventory as screening instrument for adolescent depression. JAbnorm Child Psychol. 1988;16:263-273.

26. Marton P, Churchard M, Kutcher S, Korenblum M. Diagnostic utility of the Beck Depression Inventory with adolescent psychiatric outpatients and inpatients. Can J Psychiatry. 1991;36:428-431.
27. Roberts RE, Lewinsohn PM, Seeley JR. Screening for adolescent depression: a comparison of depression scales. J Am Acad Child Adolesc Psychiatry. 1991;30:58-66.

28. Radloff LS. The CES-D scale: a self-report depression scale for research in the general population. Appl Psychol Meas. 1977;1:385-401.

29. Dierker L, Albano AM, Clarke GN, et al. Screening for anxiety and depression in early adolescence. J Am Acad Child Adolesc Psychiatry. 2001;40(8):929-936.

30. Garrison CZ, Addy CL, Jackson KL, McKeown RE, Waller JL. The CES-D as a screen for depression and other psychiatric disorders in adolescents. J Am Acad Child Adolesc Psychiatry. 1991;30: 636-641.

31. Roberts RE, Andrews JA, Lewinsohn PM, Hops H. Assessment of depression in adolescents using the Center of Epidemiologic Studies Depression Scale. Psychol Assess. 1990;2:122-128.

32. Kovacs M. Children's Depression Inventory (CDI) Manual. North Tonawanda, NY: Multi-Health Systems Inc; 1992.

33. Barreto S, McMAnus M. Casting the net for "depression" among ethnic minority children from the high-risk urban communities. Clin Psychol Rev. 1997;17:823-845.

34. Reynolds WM. Reynolds Adolescent Depressions Scales (RADS). San Antonio, TX: Harcourt Assessments/Psychological Assessment Resources; 1987.

35. Reynolds WM. Reynolds Adolescent Depression Scale. 2nd ed. San Antonio, TX: Harcourt Assessments/Psychological Assessment Resources; 2002.

36. Hamilton M. A rating scale for depression. J Neurosurg Psychiatry. 1960;23:56-62.

37. Warren WL. Revised Hamilton Rating Scale for Depression (HRSD): Manual. Los Angeles, CA: Western Psychological Services; 1997.

38. Poznanski EO, Mokros HB. Children's Depression Rating ScaleRevised (CDRS-R). Los Angeles, CA: Western Psychological Services; 1999.

39. Kaufman J, Birmaher B, Brent D, et al. Schedule for Affective Disorders and Schizophrenia for School Age Children-Present and Lifetime Version (K-SADS-PL): initial reliability and validity data. J Am Acad Child Adolesc Psychiatry. 1996;36:980-988.

40. Herjanic B, Reich W. Development of a structured psychiatric interview for children: agreement between child and parent on individual symptoms. J Abnorm Child Psychol. 1982;10:302-324.

41. Angold A, Prendergast M, Cox A, Harrington R, Simonoff E, Rutter M. The Child and Adolescent Psychiatric Assessment (CAPA). Psychol Med. 1995;25:739-753.

42. Shaffer D, Fisher P, Lucas C, Dulcan M, Schwab-Stone M. NIMH Diagnostic Interview Schedule for Children, Version IV (NIMH DISC-IV): description, differences from previous versions, and reliability of some common diagnoses. J Am Acad Child Adolesc Psychiatry. 2000;39:28-38.

43. Klein DN, Dougherty LR, Olino TM. Toward guidelines for evidencedbased assessment of depression in children and adolescents. J Clin Child and Adolesc Psychol. 2005;34:412-432.

44. Hilsenroth MJ, Segal DL, editors. Comprehensive Handbook of Psychological Assessment, Vol. 2: Personality Assessment. Hoboken, NJ: John Wiley \& Sons; 2004.

45. Hughes CW, Rintelmann J, Mayes T, Emslie GJ, Pearson G, Rush AJ. Structured interview and uniform assessment improves diagnostic reliability. J Child Adolesc Psychopharmacol. 2000;10:119-131.

46. Lewczyk CM, Garland AF, Hurlburt MS, Gearity J, Hough RL. Comparing DISC-IV and clinician diagnoses among youth receiving public mental health services. J Am Acad Child Adolesc Psychiatry. 2003;42:349-356.

47. Hazell P, O'Connell D, Heathcote D, Henry DA. Tricyclic drugs for depression in children and adolescents. Cochrane Database Syst Rev. 2002;(2):CD002317. doi:10.1002/14651858.CD002317.

48. Wagner KD. Pharamcotherapy for major depression in children and adolescents. Prog Neuropsychopharmacol Biol Psychiatry. 2005;29: 819-829. 
49. Emslie GJ, Rush AJ, Weinberg WA, Kowatch RA, Carmody T, Rintelmann J. A double-blind, randomized clinical trial of fluoxetine in children and adolescents with depression. Arch Gen Psychiatry. 1997;54:1031-1037.

50. Emslie GJ, Heiligenstein JH, Wagner KD, et al. Fluoxetine for acute treatment of depression in children and adolescents: a placebo-controlled, randomized clinical trial. J Am Acad Child Adolesc Psychiatry. 2002;41:1205-1215.

51. March J, Silva S, Petrycki S, et al. Fluoxetine, cognitive-behavioral therapy, and their combination for adolescents with depression: Treatment for Adolescents with Depression Study (TADS) randomized controlled trial. JAMA. 2004;292:807-820.

52. Emslie GJ, Ventura D, Korotzer A, Tourkodimitris S. Escitalopram in the treatment of adolescent depression: a randomized placebocontrolled multisite trial. J Am Acad Child Adolesc Psychiatry. 2009; 48:721-729.

53. Wagner KD, Robb RS, Findling RL, Jin J, Gutierrez M, Heydorn WE. A randomized, placebo-controlled trial of citalopram for the treatment of major depression in child and adolescents. Am J Psychiatry. 2004; 161:1079-1083.

54. Hammad TA, Laughren T, Judith R. Suicidality in pediatric patients treated with antidepressant drugs. Arch Gen Psychiatry. 2006;63: 332-339.

55. Whittington CJ, Kendall T, Fonagy P, Cottrell D, Cotgrove A, Boddington E. Selective serotonin reuptake inhibitors in childhood depression: systematic review of published versus unpublished data. Lancet. 2004; 366:1341-1345.

56. US Food and Drug Administration. Relationship between psychotropic drugs and pediatric suicidality: review and evaluation of clinical data. Available from: http://www.fda.gov/OHRMS/DOCKETS/AC/04/ briefing/2004-4065b1-10-TAB08-Hammads-Review.pdf Accessed Feb 9, 2010.

57. Bridge JA, Iyengar S, Salary CB, et al. Clinical response and risk for reported suicidal ideation and suicide attempts in pediatric antidepressant treatment: a meta-analysis of randomized control trials. JAMA. 2007;297:1683-1696.

58. Gibbons RD, Hur K, Bhaumik DK, Mann JJ. The relationship between antidepressant prescription rates and rate of early adolescent suicide. Am J Psychiatry. 2006;163:1898-1904.

59. Weersing VR, Brent DA. Cognitive behavioral therapy for depression in youth. Child Adolesc Psychiatr Clin N Am. 2006;15:939-957.

60. David-Ferdon C, Kaslow N. Evidenced-based psychosocial treatments for child and adolescent depression. J Clin Child Adolesc Psychol. 2008;37:62-104.

61. Clarke G, Lewinsohn PM, Hops, H. Adolescent Coping with Depression Course. Eugene, OR: Castilia Press; 1990

62. Brent D, Poling K. Cognitive Therapy Treatment Manual for Depressed and Suicidal Youth. Pittsburgh, PA: University of Pittsburgh, Services for Teens at Risk; 1997.

63. Vostanis P, Harrington R. Cognitive-behavioural treatment of depressive disorder in child psychiatric patients: rationale and description of a treatment package. Eur Child Adolesc Psychiatry. 1994;3:111-123.

64. Stark KD, Hargrove J, Hersh J, Greenberg M, Herren J, Fisher, M. Treatment of childhood depression: The ACTION treatment program. In: Abela JRZ, Hankin BL, editors. Handbook of Depression in Children and Adolescents. New York, NY: Guilford Press; 2008;224-249.

65. Weisz JR, Southam-Gerow MA, Gordis EB, Connor-Smith J. Primary and secondary control enhancement training for youth depression: applying the deployment-focused model of treatment development and testing. In: Kazdin AE, Weisz JR, eds. Evidence-Based Psychotherapies for Children and Adolescents. New York, NY: Guilford Press; 2003;165-182.

66. Lewinsohn PM, Clarke GN, Hops H, Andrews J. Cognitive-behavioral group treatment of depression in adolescents. Behav Ther. 1990;21: $385-401$.
67. Clarke GN, Rohde P, Lewinsohn PM, Hops H, Seeley JR. Cognitive-behavioral treatment of adolescent depression: efficacy of acute group treatment and booster sessions. J Am Acad Child Adolesc Psychiatry. 1999;38:272-279.

68. Rohde P, Clarke GN, Mace DE, Jorgensen JS, Seely JR. An efficacy/ effectiveness study of cognitive-behavioral treatment for adolescents with comorbid major depression and conduct disorder. J Am Acad Child Adolesc Psychiatry. 2004;43:660-668.

69. Rossello J, Bernal G, Rivera-Medina, C. Individual and group CBT and IPT for Puerto Rican adolescents with depressive symptoms. Cultur Divers Ethnic Minor Psychol. 2008;14:234-245.

70. Clarke GN, Lewinsohn PM. Instructor's Manual for the Adolescent Coping Skills Course. Portland, OR: Oregon Health Sciences University; 1995.

71. Clarke GN, Hawkins W, Murphy M, Sheeber LB, Lewinsohn PM, Seeley JR. Targeted prevention of unipolar depressive disorder in an at-risk sample of high school adolescents: a randomized trial of a group cognitive intervention. J Am Acad Child Adolesc Psychiatry. 1995;34:312-321.

72. Clarke GN, Hornbrook M, Lynch F, et al. A randomized control trial of a group of cognitive interventions for preventing depression in adolescent offspring of depressed parents. Arch Gen Psychiatry. 2001; 58:1127-1134.

73. Garber J, Clarke G, Weersing VR, et al. Prevention of depression in at risk-adolescents: a randomized controlled trial. JAMA. 2009; 301:2215-2224.

74. Cuijpers P, Muñoz RF, Clarke GN, Lewinsohn PM. Psychoeducational treatment and prevention of depression: the "Coping with Depression" course thirty years later. Clin Psychol Rev. 2009;29:449-458.

75. Weersing VR, Rozenman M, Gonzalez A. Core components of therapy in youth: do we know what to disseminate? Behav Modif. 2009; 33:24-47.

76. Brent DA, Holder D, Kolko D, et al. A clinical psychotherapy trial for adolescent depression comparing cognitive, family, and supportive therapy. Arch Gen Psychiatry. 1997;54:877-885.

77. Birmaher B, Brent DA, Kolko, D, et al. Clinical outcome after shortterm psychotherapy for adolescents with major depressive disorder. Arch Gen Psychiatry. 2007;57:29-36.

78. Wood A, Harrington R, Moore, A. Controlled trial of a brief cognitive-behavioural intervention in adolescent patients with depressive disorders. J Child Psychol Psychiatry. 1996;37: 737-746.

79. Kerfoot M, Harrington R, Harrington V, Rogers J, Verduyn C. A step too far? Randomized trial of cognitive behavioral therapy delivered by social workers for depressed adolescents. Eur Child Adolesc Psychiatry. 2004;13:92-99.

80. Mufson L, Dorta KP, Moreau D, Weissman MM. Interpersonal Psychotherapy for Depressed Adolescents. New York, NY: Guilford Press; 2004.

81. Mufson L, Weissman M, Moreau D, Garfinkel R. Efficacy of IPT for depressed adolescents. Arch Gen Psychiatry. 1999;56:573-579.

82. Mufson L, Dorta KP, Wickramaratne P, Nomura Y, Olfson M, Weissman M. A randomized effectiveness trial of interpersonal psychotherapy for depressed adolescents. Arch Gen Psychiatry. 2004;61:577-585.

83. Rosselló J, Bernal G. The efficacy of cognitive behavioral and interpersonal treatments for depression in Puerto Rican adolescents. J Consult Clin Psychol. 1999;67:734-745.

84. Diamond GS, Reis BF, Diamond GM, Siqueland L, Isaacs L. Attachment-based family therapy for depressed adolescents: a treatment development study. J Am Acad Child Adolesc Psychiatry. 2002;41:1190-1196.

85. Diamond GS, Levy SA, Israel P, Diamond GM. Attachment-based family therapy for depressed adolescents. In:Essau CA, editor. Treatments for Adolescent Depression: Theory and Practice. New York, NY: Oxford University Press; 2009:215-237. 
86. Diamond GS, Wintersteen MB, Brown GK, et al. Attachment-based family therapy for adolescents with suicidal ideation: a randomized controlled trial. J Am Acad Child Adolesc Psychiatry. 2010;49: $122-131$.

87. Weisz JR, McCarty CA, Valeri SM. Effects of psychotherapy for depression in children and adolescents: a meta-analysis. Psychol Bull. 2006;132:132-149.

88. McCarthy CA, Weisz JR. Effects of psychotherapy for depression in children and adolescents: what we can (and can't) learn from metaanalysis and component profiling. JAm Acad Child Adolesc Psychiatry. 2007;46:879-886.

89. Clarke C, Debar L, Lynch F, et al. A randomized effectiveness trial of brief cognitive-behavioral therapy for depressed adolescents receiving antidepressant medication. JAm Acad Child Adolesc Psychiatry. 2005; 44:888-898.

90. Kennard B, Silva S, Vitiello B, Curry J, Kratochvil C, Simons A. Remission and residual symptoms after short-term treatment of adolescents with depression study (TADS). J Am Acad Child Adolesc Psychiatry. 2006;45:1404-1411.

91. Brent D. Glad for what TADS adds, but many TADS grads still sad. J Am Acad Child Adolesc Psychiatry. 2006;45:1461-1464.

92. Curry JF, Wells KV, Brent DA, et al. Adolescent CBT Manual. Durham, NC: Duke University; 2000.

93. Brent D, Emslie G, Clarke G, et al. Switching to another SSRI or to venlafaxine with or without cognitive behavioral therapy for adolescents with SSRI-resistant depression: the TORDIA randomized controlled trial. JAMA. 2008;299:901-913.

94. American Academy of Child and Adolescent Psychiatry. Practice parameter for the assessment and treatment of children and adolescents with depressive disorders. JAm Acad Child Adolesc Psychiatry. 2007; 46:1503-1526.
95. Weisz JR, Doss AJ, Hawley KM. Youth psychotherapy outcome research: a review and critique of the evidence base. Annu Rev Psychol. 2005;56:337-363.

96. Bernal G, Scharrón-Del-Río MR. Are empirically supported treatments valid for ethnic minorities? Toward an alternative approach for treatment research. Cultur Divers Ethnic Minor Psychol. 2001;7: 328-342.

97. Hall GCN. Psychotherapy research with ethnic minorities: empirical, ethical, and conceptual issues. J Consult Clin Psychol. 2001;69. 502-510.

98. Kovacs M, Feinberg TL, Crouse-Novack MA, Paulauskas SL, Pollock M, Finkelstein R. Depressive disorders in childhood: II. A longitudinal study of the risk for a subsequent major depression. Arch Gen Psychiatry. 1984;41:643-649.

99. Lewinsohn PM, Clarke G, Seeley JR, Rohde P. Major depression in community adolescents: age at onset, episode duration, and time to recurrence. J Am Acad Child Adolesc Psychiatry. 1994;33:809-818.

100. McCauley E, Myers K, Mitchell J, Calderon R, Schloredt K, Treder R. Depression in young people: initial presentation and clinical course. J Am Acad Child Adolesc Psychiatry. 1993;32:714-722.

101. The Treatment for Adolescents with Depression Study Team. Treatment for adolescents with depression (TADS): rationale, design, and methods. J Am Acad Child Adolesc Psychiatry. 2003;42:531-542.

102. Kennard BD, Silva SG, Tonev S, et al. Remission and recovery in the treatment for adolescents with depression study (TADS): acute and long-term outcomes. J Am Acad Child Adolesc Psychiatry. 2009; 48:186-195.

103. Vitiello B. Treatment of adolescent depression: what we have come to know. Depress Anxiety. 2009;26:393-395.
Adolescent Health, Medicine and Therapeutics

\section{Publish your work in this journal}

Adolescent Health, Medicine and Therapeutics is an international, peer-reviewed, open access journal focusing on health, pathology, and treatment issues specific to the adolescent age group. All aspects of health maintenance, preventative measures and disease treatmen interventions are addressed within the journal and practitioners from

\section{Dovepress}

all disciplines are invited to submit their work as well as healthcare researchers and patient support groups.. The manuscript management system is completely online and includes a very quick and fair peerreview system. Visit http://www.dovepress.com/testimonials.php to read real quotes from published authors. 